Please do not remove this page

RMIT

UNIVERSITY

\title{
Work-life strategies in the Australian construction industry: Implementation issues in a dynamic project-based work environment
}

Lingard, H., Francis, V., \& Turner, M. (2012). Work-life strategies in the Australian construction industry: Implementation issues in a dynamic project-based work environment. International Journal of Project Management, 30(3), 282-295. https://doi.org/10.1016/j.ijproman.2011.08.002 Document Version: Accepted Manuscript

Published Version: https://doi.org/10.1016/j.ijproman.2011.08.002

Repository homepage: https://researchrepository.rmit.edu.au (C) 2011 Elsevier Ltd.

Downloaded On 2023/04/27 00:07:27 +1000 
Thank you for downloading this document from the RMIT Research Repository.

The RMIT Research Repository is an open access database showcasing the research outputs of RMIT University researchers.

RMIT Research Repository: http://researchbank.rmit.edu.au/

\section{Citation:}

Lingard, H, Francis, V and Turner, M 2012, 'Work-life strategies in the Australian construction industry: Implementation issues in a dynamic project-based work environment', International Journal of Project Management, vol. 30, no. 3, pp. 282-295.

See this record in the RMIT Research Repository at:

https://researchbank.rmit.edu.au/view/rmit:14720

Version: Accepted Manuscript

Copyright Statement: (C) 2011 Elsevier Ltd. Licensed under the Creative Commons Attribution-NonCommercial-NoDerivatives 4.0 International http://creativecommons.org/licenses/by-nc-nd/4.0/

Link to Published Version:

http://dx.doi.org/10.1016/j.ijproman.2011.08.002 


\title{
Work-life strategies in the Australian construction industry: Implementation issues in a dynamic project-based work environment
}

\author{
Helen Lingard, Valerie Francis, Michelle Turner
}

\begin{abstract}
A participatory work-life balance intervention was implemented in a medium-sized construction contracting organization based in Melbourne, Australia. Weekly data capturing the number of hours worked, satisfaction with work-life balance and capacity to complete required tasks at work and at home were collected for 25 consecutive weeks. Data was subjected to time series modelling procedures and weekly work hours were found to significantly predict participants' overall satisfaction with work-life balance, and capacity to complete tasks at work and at home. The occurrence of 'long weekends', i.e., a period of three days away from work arising as a result of a public holiday coinciding with a 'rostered day off', was also found to predict workers' capacity to complete tasks at home. An evaluation workshop explored workers' experiences of the work-life intervention. Participants' were generally positive about the organization's support of their work-life balance, however areas for improvement were identified, such as the need for better communication of work-life strategies and to address the 'long hours' culture within the organization. The research presents a participatory framework for improving the work-life balance of project-based construction workers.
\end{abstract}

\section{Keywords}

Work-life strategies, hours, work-family balance, project work

\section{Introduction}

\section{Aims}

Work-life balance is a key challenge facing organizations in the $21^{\text {st }}$ Century. Almost all work-life balance research has taken place in 'steady-state' work environments and utilised a cross-sectional research design. Consequently, little is known about the work-life experiences of workers in dynamic project-based industries, despite the fact that project work is understood to have unique characteristics and demands. Further, the few previous attempts that have sought to create a better understanding worklife balance in project environments have been purely descriptive in nature (see, for example, Lingard and Francis, 2004; Perlow, 1998). Brough and O'Driscoll (2010) argue that there is a need to move beyond descriptive investigations of work-life balance to undertake research that trials and evaluates organizational interventions to improve work-life balance.

The aim of the research was to address these knowledge gaps in two respects. The research explored work-family experiences using a weekly reporting technique that captured the experiences of projectbased workers over time. In addition to the dynamic measurement of work-life experiences, a participatory work-life intervention was implemented and evaluated in the context of a medium-sized construction contracting organization in Australia. Specific research objectives were: (i) to implement and evaluate a number of strategies designed to improve work-life balance in the contracting organization over the research period; and (ii) to identify factors that facilitated and/or impeded the implementation of the intervention in the context of the contracting organization.

\section{The construction industry context}

The construction industry is a high risk industry for work stress associated with excessive workloads, time constraints and deadlines (Sutherland and Davidson 1989; Leung et al. 2007). Work stress has been linked to lower levels of performance in construction project managers (Djebarni,1996; Leung et al. 2008). Ng et al. (2005) identify work-family conflict as one of the least easily managed work stressors experienced by construction professionals. Similarly, Haynes and Love (2004) identify long hours, workload and insufficient time spent with family as the three most significant stressors experienced by construction managers in Australia. Lingard et al. (2010a) report that time- and strain-based work interference with family are higher among Australian construction workers than among other occupational groups in international research. 


\section{Project-based work}

Within the construction industry researchers report significant variation in the experience of work stress between different groups of workers. Love et al. (2010) found that workers employed by construction contractors suffer higher levels of work stress than workers employed by consulting organizations. In an analysis of public and private sector construction workers, Lingard and Francis (2004) found that projectbased workers experience significantly longer hours, higher levels of work-family conflict and burnout than their office-based counterparts. Project work is dynamic, fast-paced and subject to periods of high intensity and the occurrence of unexpected events (Aitken and Crawford, 2007; Asquin et al., 2010). Mohr and Wolfram (2010) report that dynamic tasks are associated with higher levels of stress in managers, especially when unexpected problems arise. Lindgren and Packendorff (2006) reflect on the 'greediness' of project work in the IT industry which prevents workers from engaging in stimulating activities outside work. Long hours combined with tight deadlines significantly increase the extent to which work negatively impacts upon family life (Wharton and Blair-Loy, 2006). One feature of projects is the occurrence of critical points, prior to which work intensifies, impacting on work hours and worklife balance (Perlow, 1998; Lingard et al., 2010b).

\section{Work-life strategies}

There is a growing interest in the provision of work-life strategies within organizations. Previous research suggests that organizations that provide a 'family-friendly' work environment benefit significantly in terms of decreased turnover intention and increased organizational commitment (Grover and Crooker, 1995; Thompson et al., 1999) and increased job satisfaction (Allen, 2001; Breaugh and Frye, 2007). Work-life strategies are designed to 'help employees with many facets of their lives, including their personal well-being, professional development and family responsibilities' (Muse et al. 2008, p. 29). Thus they are not just focused on workers with family responsibilities. Work-life strategies can include childrelated supports, childhood health programmes, maternity and paternity leave, flexible work scheduling, physical well-being programmes, psychological well-being programmes and eldercare assistance. Halpern (2005) reports that the greater the number of work-life strategies an organization offers, the more loyal employees are, the fewer stress symptoms they report and the lower the costs incurred due to days late, missed deadlines and absenteeism. Research also indicates that organizations offering a supportive worklife balance environment through the implementation of work-life strategies are better positioned to attract employees when recruiting new staff (Casper and Buffardi, 2004; Thompson and Aspinwall, 2009).

\section{Utilization of work-life strategies}

The business case for work-life strategies depends upon the extent to which these strategies are valued and utilized by workers (Blair-Loy and Wharton, 2004). However, research shows that utilization rates of work-life strategies are often low (Swody and Powell, 2007). Patterns of take-up of work-life strategies are shaped by the organizational culture, in particular, perceptions of managerial support and expectations about potential (negative) career consequences for users (Thompson et al., 1999). Beliefs about the 'legitimacy' of strategy use are also shaped by discourse within workgroups (Kirby and Krone, 2003; Blair-Loy and Wharton, 2004), creating informal peer pressure that can militate against strategy utilization. The utilization of strategies is also related to workers' individual characteristics, such as family status and the extent to which available strategies provide a good 'fit' with workers' needs (Shockley and Allen, 2010).

\section{The research context}

Data collection took place within a medium-sized construction contracting organization based in Melbourne, Australia, between October 2009 and December 2010. Data were collected from waged and salaried workers engaged in two commercial building projects, one small civil engineering project and corporate office-based work, primarily related to tendering for new projects. Both salaried and waged workers from the three projects moved between projects. 


\section{Research methods}

Research design

An 'action research' approach was adopted using a structured and participatory intervention process recommended by Nielsen et al. (2010). Action research utilizes external persons (the research team) to consult with organizational stakeholders (e.g. managers and workers) to produce and evaluate an intervention (Brough and O'Driscoll, 2010). Workers and managers are treated as co-learners during the research process and 'ownership' of the intervention is transferred from researchers to members of the organization (Rapoport et al. 2002).

Steps in the research process were:

(1) Baseline Survey (survey one): a work-life survey was initially conducted at the project. The survey measured initial perceptions of work-family conflict (work interference with family and family interference with work) and work-family enrichment prior to the implementation of any work-life balance interventions.

(2) Weekly data collection: the quality of work-family interaction throughout the duration of the research was captured through a weekly self-report measurement method. Participants were requested to complete a small number of questions on a weekly basis to ascertain fluctuations in work-life experiences over time. (3) Work-Life Workshop One: this workshop focused on the awareness of work-life balance issues. Data from survey one was used as a starting point in the workshop. Participants then took information presented back to their representative work areas to discuss workers' preferences for work-life balance strategies. (4) Work-Life Workshop Two: this workshop focused on developing a list of recommended work-life strategies for the project (based on the feedback from the workforce). This list was then provided to the organization's management team which decided which strategies to implement.

(5) Work-Life Workshop Three: the third workshop evaluated the effectiveness of the strategies implemented within the organization and explored barriers to work-life balance.

(6) Follow-up Survey (survey two): the work-family survey was repeated and the results of survey one and survey two were compared to ascertain whether: (i) a reduction in perception of work-family conflict; and/or (ii) an increase in work-family enrichment had occurred within the organization.

Figure 1 shows the timing of research activities at the contracting organization. 
Figure 1: Timing of research activities

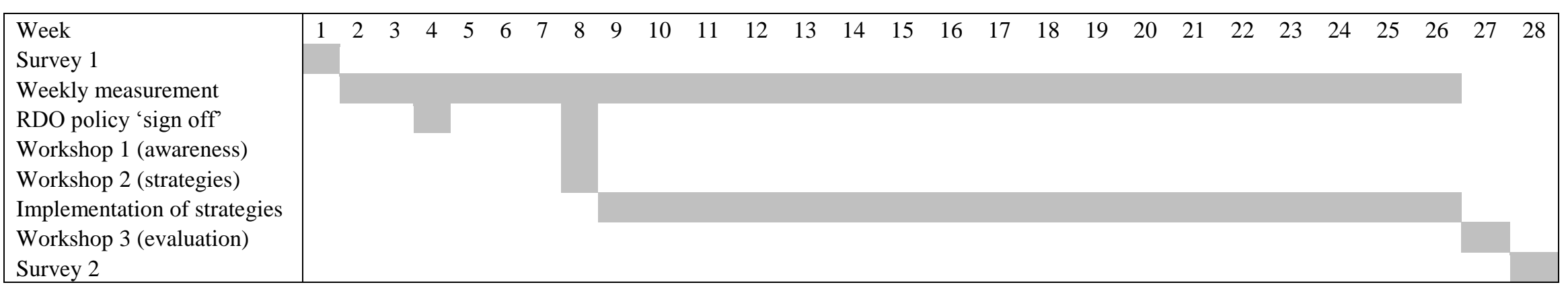




\section{Survey data collection}

Participants were asked to indicate their sex, age and the number of children they have. To distinguish between the presence of dependent and non-dependent children, participants were asked to indicate how many children they have under the age of 18 and aged 18 years or over. Participants were also asked to indicate how many hours on average they work each week.

Work-family conflict (WFC) was measured using a scale developed by Carlson et al. (2000). This scale comprises six subscales. Each direction of WFC (i.e., work-interference-with-family and familyinterference-with-work) is nested within three dimensions of conflict (i.e., time-based, strain-based and behaviour-based). Each subscale comprises three items. Example items are: (i) "My work keeps me from my family activity more than I would like" (time-based work-interference-with-family); (ii) "The times I spend on family responsibilities often interferes with my work responsibilities" (time-based familyinterference-with-work); (iii) "I am often so emotionally drained when I get home from work that it prevents me from contributing to my family" (strain-based work-interference-with-family); (iv) 'Because I am often stressed from family responsibilities I have a hard time concentrating on my work" (strainbased family-interference-with-work); (v) "Behaviour that is necessary and effective for me at work would be counterproductive at home" (behaviour-based work-interference-with-family); and (vi) "The behaviours that work for me at home do not seem to be effective at work" (behaviour-based familyinterference-with-work). Responses were provided on a five point scale ranging from strongly disagree (1) to strongly agree (5). Owing to the fact that the sample was heterogeneous, one item was removed from the dataset prior to analysis. The wording of this item (The behaviours I perform that make me effective at work do not help me to be a better parent and spouse) suggested that respondents were partnered with children, which was not the case in the contracting organization sample. Thus, only two behaviour-based work-interference with family (WIF) items were included in the data analysis. Work-family enrichment was measured using six items drawn from the National Survey of Midlife Development in the United States, as cited in Grzywacz and Marks (2000). This scale was used by Wayne et al. (2004) and Innstrand et al. (2008) to measure work-family facilitation and was used by Grzywacz and Butler (2005) as a measure of positive spillover between work and family, illustrating the way in which these terms have been used interchangeably in previous research. However, the items imply a transfer of energy or behaviours that also improve performance in the other role (Hanson et al., 2006). Thus, we refer to this as work-family enrichment in accordance with the conceptual definitions of positive work-family interaction provided by Carlson et al. (2006) and Wayne et al. (2007). Example items include 'The things I do at work help me deal with personal and practical issues at home' and 'Talking with someone at home helps me deal with problems at work'. Participants were asked to indicate how often they experienced these circumstances in the past year. The items were scored on a five-point scale ranging from one (never) to five (all of the time).

\section{Weekly data collection}

Participants were invited to complete a weekly 'work-life report card' over a 25-week period. Primarily, this 'report card' captured quantitative information about work-life experiences using three Likert scale items. Items included: (i) 'All things considered, how satisfied have you been with your work-life balance this week?' which was rated on a seven-point scale from 'very dissatisfied' (1) to 'very satisfied' (7); (ii) 'In the past week how frequently have you felt rushed and unable to complete all that was required at work?' and (iii) 'In the past week how frequently have you felt rushed and unable to complete all that was required at home?' The latter two items were rated on a seven-point scale from 'all the time' (1) to 'not at all' (7). Participants were asked to indicate how much time they spent engaged in work during the week of the 'report card' entry. Work hours were rated in eight increments from 'less than 35 hours' to 'more than 65 hours'. Interim ratings were in five-hour increments, e.g. 35-40 and 41-45 hours. Participants were also asked to provide additional explanatory comments if they wished to do so.

\section{The benefits of dynamic data collection}

Frequently repeated measurement is increasingly used to explore experiences at the interface between work and personal life. Frequently repeated measurement tools are useful for assessing processes in 
everyday life because they are subject to less retrospective bias (Bolger et al., 2003) and enable even small changes to be detected. Williams and Alliger (1994) proposed three levels of analysis of the workfamily experience: (i) immediate experiences, current thoughts and feelings and events that are happening in the present; (ii) short-term judgements where a person only has a short time to reflect upon their experiences; and (iii) global, long-term evaluations of their experiences. Surveys are useful to measure general patterns of stable variables of interest (i.e. level 3 analysis) but frequently repeated measurement methods are arguably more useful in providing detailed information about work and family experiences (i.e. level 2 analysis). For example, Van Hooff et al. (2006) and Sanz-Vergel et al. (2009) utilized a daily diary method to explore the relationship between daily pressures, recovery, work-family conflict and exhaustion. Frequently repeated measurement methods are particularly useful in work-life research because the interface between work and family life is not static (Butler et al., 2005). A frequently repeated measurement approach is ideally suited to the analysis of workload fluctuations and work-life experiences in the dynamic project-based environment of a construction contracting environment.

\section{The work-life balance intervention}

The intervention commenced with a workshop presenting the results of the baseline (time one) survey to a mixed and representative group of waged and salaried workers within the contracting organization. Feedback sessions were held in the head office, as well as at the organization's project worksite locations. The results of the survey were used to prompt discussion of work-life balance challenges and participants were asked to consider strategies that would help them to better balance their work and non-work lives.

Following a period of consultation, three work-life strategies were decided upon and implemented during the research period. The first strategy involved the clarification of the rostered day off (RDO) policy for project-based salaried staff. Rostered days off are a feature of the industrial environment in the Australian construction industry and provide routine rest days from work on a fortnightly basis to project-based workers who typically work a six day week between Monday and Saturday. Thus, an industry-wide industrial agreement provides for a rest on alternate Mondays. Traditionally these rest days have only been available to waged construction workers, while salaried workers (mostly supervisors, managers and professional workers) have not been entitled to rostered days off. In the contracting organization a new policy was implemented during the research period allowing project-based salaried workers to take rostered days off, i.e. to have alternate Mondays off work. The policy was updated and signed off by the managing director and communicated to staff during week four of the research. The second strategy involved a leadership session for managers which focused on mentoring behaviour to support subordinates' work-life balance, such as encouraging workers to leave work at a reasonable hour. This strategy was implemented from week eight of the research period. The third strategy was the implementation of a 'policy' which stipulated that workers should take a break prior to the commencement of an intense work period. This was implemented from week nine of the research period.

The staggered intervals at which the strategies was introduced was a deliberate feature of the research design. This would enable the 'effects' of each strategy to be evaluated, i.e., if an improvement in worklife experiences occurred after week four, this may be attributed to the RDO policy implementation, if an improvement was observed after week eight, this could be attributed to the leadership/mentoring session and if an improvement was observed after week nine, it could be attributed to the policy permitting project workers to take a break during less intense periods of work.

\section{Evaluation workshop}

On $7^{\text {th }}$ September 2010, an evaluation workshop of approximately one hour duration was conducted with seven workers of the construction contracting organization. Small group evaluations have previously been advocated by researchers for the evaluation of organizational interventions in the areas of stress and occupational health (see, for example, Randall et al., 2007). The workshop was facilitated by a researcher and data were recorded and transcribed prior to analysis. Participants were asked open-ended questions about the effectiveness of strategies implemented at the organization. The workshop also explored worklife balance experiences within the organization, factors facilitating the effectiveness of work-life intervention and barriers impeding the effectiveness of the work-life intervention. 


\section{Data analysis}

Survey data collected using the multidimensional work-family conflict scale was analyzed using a principal components analysis (PCA) with varimax rotation. PCA assumes that underlying dimensions or factors can be used to explain complex phenomena. The goal of PCA is to identify the not-directly observable factors based on a set of observable or measurable indicators. Mean scores for the resulting three dimensions of WFC, i.e., time and strain-based work interference with family (WIF), time and strain-based family interference with work (FIW) and behaviour-based work-family conflict (WFC) were calculated. Mean scores for family-to-work enrichment and work-to-family enrichment were also calculated. Internal consistency for each of the multi-item scales was assessed by calculating Cronbach's alpha coefficients. Independent samples t-tests were conducted to compare work-family conflict and enrichment scores between the baseline (time one) and follow up (time two) surveys. Time series data are often characterized by properties that violate the assumptions underlying traditional statistical models (Gottman and Glass, 1978; Hartmann et al., 1980). Multivariate time series analysis was conducted to ascertain the extent to which work hours and/or the implementation of the work-life strategies predicted satisfaction with work-life balance and capacity to complete tasks at work and home. Qualitative data collected during the evaluation workshop was transcribed and subjected to thematic content analysis.

\section{Results}

\section{Survey results}

During October, November and December 2009, 92 participants completed the first of the two work-life surveys. During September, October and November 2010 the survey was re-administered to 55 participants. Data collection was performed using the 'TurningPoint' automated response system with 'KeyPad' hand held devices.

At time one, $86(93.5 \%)$ of the survey respondents were male and six $(6.5 \%)$ were female. Thirty five respondents $(38.0 \%)$ were aged 30 years or younger. Twenty nine respondents $(31.5 \%)$ were aged between 31 and 40, thirteen respondents (14.1\%) were aged between 41 and 50 and thirteen respondents $(14.1 \%)$ were over the age of 50. The majority of respondents $(n=69,75.0 \%)$ were partnered and 22 (23.9\%) indicated they were single. Forty six respondents $(50.0 \%)$ indicated that they were parents, while 45 (48.9\%) were child-free. Of the participants with dependent children (i.e., those under the age of 18), ten respondents $(10.9 \%)$ reported having one dependent child, thirteen respondents $(14.1 \%)$ had two dependent children and eight respondents $(8.7 \%)$ had three dependent children. Sixty respondents $(65.2 \%)$ indicated that they had no dependent children. Forty three respondents $(46.7 \%)$ reported working in excess of 50 hours per week, while an additional 32 respondents $(34.8 \%)$ indicated they work between 40 and 50 hours per week

At time two, $46(83.6 \%)$ of the survey respondents were male and nine (16.4\%) were female. Twenty seven respondents $(49.1 \%)$ were aged 30 years or younger. Fifteen respondents $(27.3 \%)$ were aged between 31 and 40, eight respondents (14.5\%) were aged between 41 and 50 and five respondents $(9.1 \%)$ were over the age of 50 . The majority of respondents $(n=37,67.3 \%)$ were partnered and eighteen $(32.7 \%)$ indicated they were single. Twenty three respondents (41.8\%) indicated that they were parents, while 32 $(58.2 \%)$ were child-free. Of the participants with dependent children (i.e., those under the age of 18), five respondents $(9.1 \%)$ reported having one dependent child, nine respondents (16.4\%) had two dependent children, three respondents $(5.5 \%)$ had three dependent children and one respondent $(1.8 \%)$ had four or more dependent children. Thirty seven respondents $(67.3 \%)$ indicated that they had no dependent children. Twenty nine respondents $(52.7 \%)$ reported working in excess of 50 hours per week, while an additional 14 respondents $(25.5 \%)$ indicated they work between 40 and 50 hours per week

Table 1 shows the results of the principal components analysis of data collected using the work-family conflict scale. Time- and strain-based work-interference with family (WIF) items loaded together on the first factor (explaining most of the variance). Time- and strain-based family interference with work (FIW) items loaded clearly and consistently on the second factor. Four of the six behaviour-based WFC (i.e. 
those describing behaviour-based WIF and FIW) loaded on the third factor. Thus, although workers in the contracting organization discriminate between time- and strain-based family interference with work and time and strain-based work interference with family, they did not discriminate between the two directions of behaviour-based conflict between work and family. The Cronbach's alpha coefficient for time and strain-based WIF was .847, for time and strain-based FIW was .854 and for behaviour-based work-family conflict was .783 , indicating acceptable internal consistency reliability.

\section{Table 1: Rotated component matrix for the work-family conflict items}

\begin{tabular}{|c|c|c|c|}
\hline & \multicolumn{3}{|c|}{ Component } \\
\hline & 1 & 2 & 3 \\
\hline $\begin{array}{l}\text { Because I am often stressed from family responsibilities, I have a hard time } \\
\text { concentrating on my work. }\end{array}$ & .820 & .153 & .175 \\
\hline $\begin{array}{l}\text { I have to miss work activities due to the amount of time I must spend on family } \\
\text { responsibilities. }\end{array}$ & .785 & .029 & .006 \\
\hline $\begin{array}{l}\text { The time I spend on family responsibilities often interfere with my work } \\
\text { responsibilities. }\end{array}$ & .775 & .182 & .031 \\
\hline Tension and anxiety from my family life often weakens my ability to do my job. & .743 & .235 & .267 \\
\hline Due to stress at home, I am often preoccupied with family matters at work. & .703 & .134 & .182 \\
\hline $\begin{array}{l}\text { The time I spend with my family often causes me not to spend time in activities at } \\
\text { work that could be helpful to my career. }\end{array}$ & .655 & .094 & .155 \\
\hline $\begin{array}{l}\text { When I get home from work I am often too frazzled to participate in family activities/ } \\
\text { responsibilities. }\end{array}$ & .149 & .767 & .249 \\
\hline $\begin{array}{l}\text { I have to miss family activities due to the amount of time I must spend on work } \\
\text { responsibilities. }\end{array}$ & .194 & .748 & .075 \\
\hline My work keeps me from my family activities more than I would like. & .003 & .746 & .065 \\
\hline $\begin{array}{l}\text { The time I must devote to my job keeps me from participating equally in household } \\
\text { responsibilities and activities. }\end{array}$ & .134 & .728 & -.027 \\
\hline $\begin{array}{l}\text { Due to all the pressures at work, sometimes when I come home I am too stressed to do } \\
\text { the things I enjoy. }\end{array}$ & .145 & .716 & .261 \\
\hline $\begin{array}{l}\text { I am often so emotionally drained when I get home from work that it prevents me } \\
\text { from contributing to my family. }\end{array}$ & .228 & .712 & .286 \\
\hline The behaviours that work for me at home do not seem to be effective at work. & .023 & .002 & .863 \\
\hline $\begin{array}{l}\text { Behavior that is effective and necessary for me at home would be counterproductive } \\
\text { at work. }\end{array}$ & .073 & .168 & .858 \\
\hline $\begin{array}{l}\text { The behaviours I perform that make me effective at work do not help me to be a better } \\
\text { family member }\end{array}$ & .144 & .152 & .701 \\
\hline $\begin{array}{l}\text { The problem-solving behaviour that works for me at home does not seem to be as } \\
\text { useful at work. }\end{array}$ & .215 & .178 & .637 \\
\hline $\begin{array}{l}\text { Behaviour that is effective and necessary for me at work would be counterproductive } \\
\text { at home. }\end{array}$ & .308 & 149 & .402 \\
\hline $\begin{array}{l}\text { The problem-solving behaviours I use in my job are not effective in resolving } \\
\text { problems at home. }\end{array}$ & .292 & .271 & .336 \\
\hline
\end{tabular}

Figure 2 shows the mean scores for each of the work-family conflict dimensions at the baseline (time one) and follow-up (time two) surveys. Scores for all three dimensions of work-family conflict were lower when the second survey was administered. The independent samples t-tests revealed that the difference between mean scores at time one and time two was not statistically significant for either time and strainbased WIF or behaviour-based work-family conflict. However, the difference between the mean time one and time two survey scores for time and strain-based FIW was significant $(t=2.366, p=.019)$. 
Figure 2: Work-family conflict at the baseline (time one) and follow up (time two) surveys

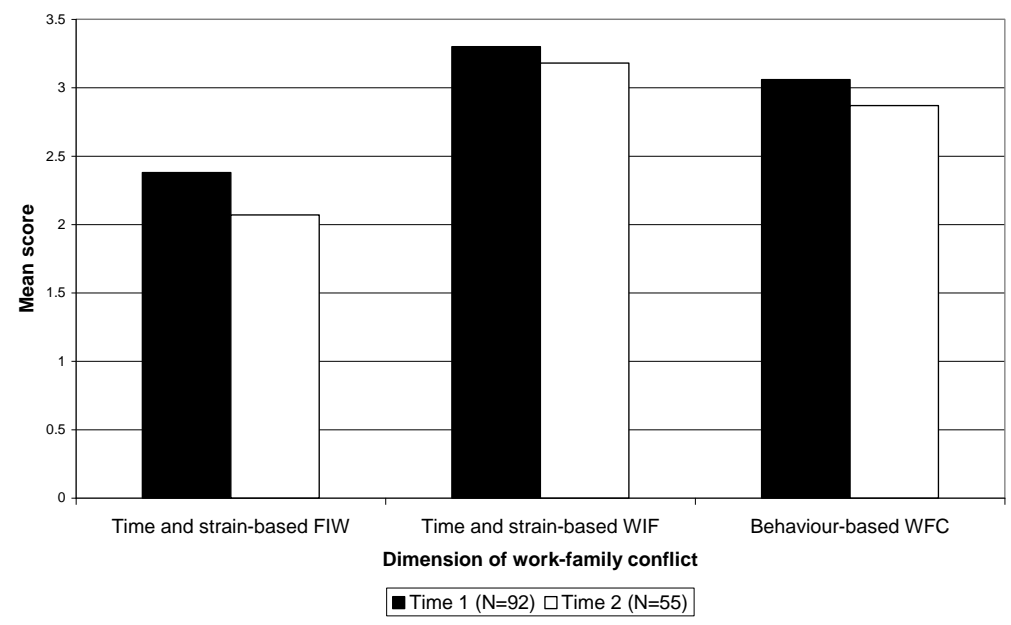

Figure 3 shows the mean scores for the two directions of work-family enrichment at the baseline (time one) and follow-up (time two) surveys. Scores for both directions of work-family enrichment were higher when the second survey was administered. However, independent samples t-tests revealed that these differences were not statistically significant.

Figure 3: Work-family enrichment at the baseline (time one) and follow up (time two) surveys

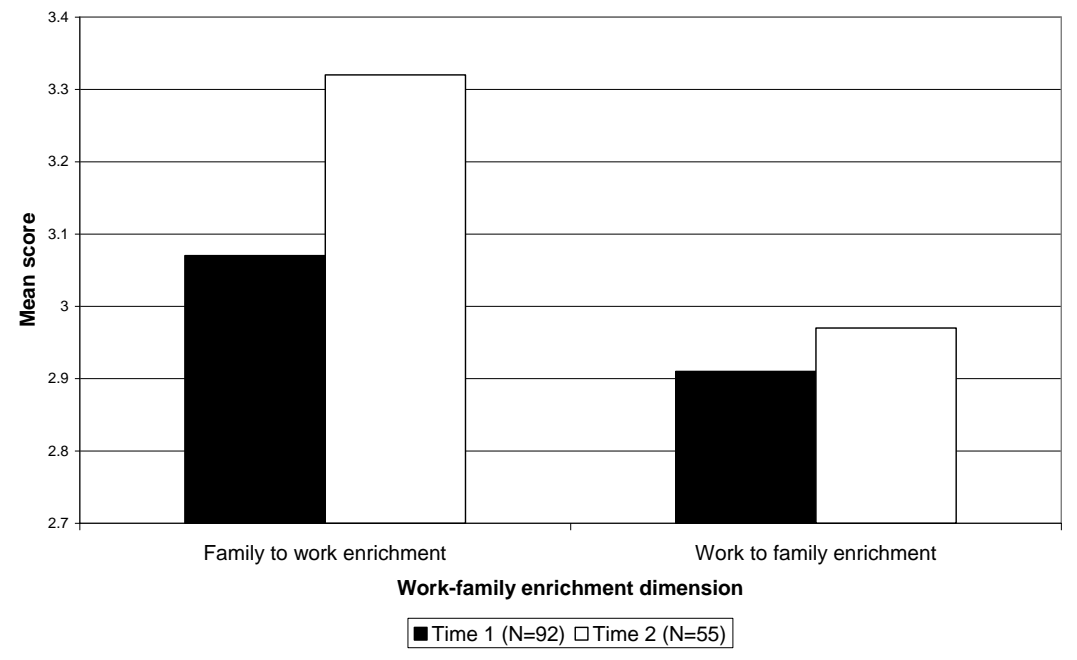

\section{Weekly report data}

Table 2 summarizes the number of responses completed per week during the weekly data collection period. The number of participants differed on a weekly basis. The average number of participants in any week was 29.4. Frequent repeated measurement methods require a high degree of participant engagement and many previous applications of this technique in work-life balance research have collected data for a considerably shorter period. For example, Van Hooff et al. (2006) and Sanz-Vergel et al. (2009) collected diary data for a period of only five consecutive days. For the purposes of the time series analysis the number of cases equals 'person-weeks' rather than 'persons,' giving an effective sample size of 734 data points. 
Table 2: Weekly responses by employment status

\begin{tabular}{|c|c|c|c|c|}
\hline Week & Date & Total & $\begin{array}{l}\text { White collar } \\
\text { (salaried) }\end{array}$ & $\begin{array}{c}\text { Blue collar } \\
\text { (waged) }\end{array}$ \\
\hline 1 & $15-21$ February 2010 & 42 & 41 & 1 \\
\hline 2 & $22-28$ February 2010 & 47 & 35 & 12 \\
\hline 3 & $1-7$ March 2010 & 38 & 26 & 12 \\
\hline 4 & $8-14$ March 2010 & 41 & 33 & 8 \\
\hline 5 & $15-21$ March 2010 & 42 & 30 & 12 \\
\hline 6 & $22-28$ March 2010 & 42 & 25 & 17 \\
\hline 7 & 29 March - 4 April 2010 & 43 & 26 & 17 \\
\hline 8 & 5-11 April 2010 & 23 & 21 & 2 \\
\hline 9 & $12-18$ April 2010 & 40 & 30 & 10 \\
\hline 10 & $19-25$ April 2010 & 17 & 16 & 1 \\
\hline 11 & 26 April - 2 May 2010 & 16 & 15 & 1 \\
\hline 12 & $3-9$ May 2010 & 34 & 21 & 13 \\
\hline 13 & $10-16$ May 2010 & 17 & 17 & 0 \\
\hline 14 & $17-23$ May 2010 & 34 & 17 & 17 \\
\hline 15 & $24-30$ May 2010 & 33 & 22 & 11 \\
\hline 16 & 21 May - 6 June 2010 & 29 & 25 & 4 \\
\hline 17 & $7-13$ June 2010 & 16 & 16 & 0 \\
\hline 18 & 14 - 20 June 2010 & 20 & 20 & 0 \\
\hline 19 & 21 - 27 June 2010 & 20 & 12 & 8 \\
\hline 20 & 28 June -4 July2010 & 15 & 15 & 0 \\
\hline 21 & $5-11$ July 2010 & 20 & 20 & 0 \\
\hline 22 & 12-18 July 2010 & 15 & 15 & 0 \\
\hline 23 & $19-25$ July 2010 & 27 & 27 & 0 \\
\hline 24 & 26 July - 1 August 2010 & 30 & 24 & 6 \\
\hline 25 & $2-8$ August 2010 & 33 & 29 & 4 \\
\hline \multicolumn{2}{|r|}{ TOTAL RESPONSES } & 734 & 578 & 156 \\
\hline
\end{tabular}

The impact of work hours and work-life interventions

To evaluate the impact of work hours and work-life interventions on participants' experiences, a technique for impact assessment recommended by Box and Tiao (1975) was used. This technique includes four stages: (1) the development of a model for a time series; (2) adding one or more 'dummy' variables that represent the timing of the events of interest; (3) re-estimating the model including the new dummy variables; and (4) interpreting the coefficients of dummy variables as measures of the impact of the interventions.

Four dummy variables were created. The first of these dummy variables represented the management 'sign off' on the policy to provide rostered days off to salaried project-based staff in week four of the data collection period. The second dummy variable (week eight onwards) represented the timing of the worklife consultation workshop, at which feedback from the baseline survey was provided for discussion and appropriate work-life strategies were selected. This was included as a dummy variable because the adoption of a participative approach to the resolution of work-life issues can be viewed as an intervention in its own right (Nielsen et al., 2010). As the implementation of work-life strategies two and three occurred in consecutive weeks, and data were collected in weekly increments, it was not possible to test separately for the 'effects' of these strategies. Thus, the second dummy variable represented the implementation of the consultation workshop, management leadership development and encouragement of workers to take appropriate breaks from work combined.

The remaining dummy variables entered into the model represented the timing of routine rostered days off in the construction industry calendar and the occurrence of 'long weekends' arising due to public holidays. The dummy variables were entered into the time series models after weekly work hours. The reason for this was to ascertain whether they were able to predict the dependent variables when any 
variance 'explained' by work hours had already been controlled for. The results are presented in Tables 3 and 4.

Table 3: Time series model statistics - weekly work hours and project events as independent variables

\begin{tabular}{|c|c|c|c|c|c|c|}
\hline \multirow[t]{2}{*}{ Dependent variable } & \multirow{2}{*}{$\begin{array}{l}\text { Number of } \\
\text { Predictors }\end{array}$} & Model Fit & \multicolumn{3}{|c|}{ Ljung-Box } & \multirow{2}{*}{$\begin{array}{c}\text { Number o } \\
\text { Outliers }\end{array}$} \\
\hline & & $\begin{array}{l}\text { Stationary R- } \\
\text { squared }\end{array}$ & Statistics & $\mathrm{DF}$ & Sig. & \\
\hline 1. Satisfaction with WLB & 1 & .575 & 16.710 & 18 & .543 & 0 \\
\hline $\begin{array}{l}\text { 2. Capacity to complete } \\
\text { tasks at work }\end{array}$ & 1 & .408 & 15.752 & 18 & .610 & 0 \\
\hline $\begin{array}{l}\text { 3. Capacity to complete } \\
\text { tasks at home }\end{array}$ & 1 & .659 & 23.708 & 18 & .165 & 0 \\
\hline
\end{tabular}

The Expert Modeler function in PASW (version 18) was used to identify the most appropriate model for each series. Table 2 shows the time series model statistics. All three models were simple 0,0,0 ARIMA models, indicating no autoregressive, differencing or moving average components. The Ljung-Box statistic was non-significant, indicating that the model was correctly specified for all three dependent variables. The R-square (goodness of fit) statistics indicate that the models explained 58\% of variance in satisfaction with work-life balance, $41 \%$ of variance in capacity to complete tasks at work and $66 \%$ of variance in capacity to complete tasks at home. Observed and predicted values are shown in Figure 1 . The predicted values show good agreement with the observed values for all three dependent variables.

Table 4: Model parameter statistics—weekly work hours and project events as predictors of satisfaction with work-life balance, capacity to complete tasks at work and capacity to complete tasks at home

\begin{tabular}{|c|c|c|c|c|c|}
\hline $\begin{array}{c}\text { Dependent } \\
\text { variables }\end{array}$ & Predictor variables & Estimate & SE & $\mathbf{t}$ & Sig. \\
\hline \multirow{6}{*}{$\begin{array}{l}\text { 1. Satisfaction } \\
\text { with WLB }\end{array}$} & Constant & 7.272 & .773 & 9.403 & .000 \\
\hline & $\begin{array}{l}\text { Weekly work hours } \\
\text { (Lag 0) }\end{array}$ & -.551 & .159 & -3.473 & .003 \\
\hline & $\begin{array}{l}\text { Announcement of RDO } \\
\text { policy (Lag 0) }\end{array}$ & -.121 & .279 & -.432 & .670 \\
\hline & $\begin{array}{l}\text { WLB Workshop One } \\
(\text { Lag 0) }\end{array}$ & -.050 & .186 & -.266 & .793 \\
\hline & Routine RDOs (Lag 0) & .033 & .133 & .246 & .808 \\
\hline & $\begin{array}{l}\text { Long weekends/public } \\
\text { holidays (Lag 0) }\end{array}$ & -.395 & .293 & -1.351 & .193 \\
\hline \multirow{6}{*}{$\begin{array}{l}\text { 2. Capacity to } \\
\text { complete tasks at } \\
\text { work }\end{array}$} & Constant & 6.923 & 1.024 & 6.758 & .000 \\
\hline & $\begin{array}{l}\text { Weekly work hours } \\
(\text { Lag 0) }\end{array}$ & -.537 & .210 & -2.558 & .019 \\
\hline & $\begin{array}{l}\text { Announcement of RDO } \\
\text { policy (Lag 0) }\end{array}$ & .054 & .369 & .148 & .884 \\
\hline & $\begin{array}{l}\text { WLB Workshop One } \\
\text { (Lag 0) }\end{array}$ & .043 & .247 & .175 & .863 \\
\hline & Routine RDOs (Lag 0) & -.162 & .177 & -.920 & .369 \\
\hline & $\begin{array}{l}\text { Long weekends/public } \\
\text { holidays (Lag 0) }\end{array}$ & -.612 & .388 & -1.579 & .131 \\
\hline \multirow{4}{*}{$\begin{array}{l}\text { 3. Capacity to } \\
\text { complete tasks at } \\
\text { home }\end{array}$} & Constant & 7.018 & .667 & 10.524 & .000 \\
\hline & $\begin{array}{l}\text { Weekly work hours } \\
\text { (Lag 0) }\end{array}$ & -.600 & .137 & -4.385 & .000 \\
\hline & $\begin{array}{l}\text { Announcement of RDO } \\
\text { policy (Lag 0) }\end{array}$ & -.114 & .240 & -.473 & .641 \\
\hline & $\begin{array}{l}\text { WLB Workshop One } \\
\text { (Lag 0) }\end{array}$ & -.054 & .161 & -.333 & .743 \\
\hline
\end{tabular}




\begin{tabular}{lcccc} 
Routine RDOs (Lag 0) & -.070 & .115 & -.607 & .551 \\
\hline $\begin{array}{l}\text { Long weekends/public } \\
\text { holidays (Lag 0) }\end{array}$ & $\mathbf{. 5 4 6}$ & $\mathbf{. 2 5 2}$ & $\mathbf{2 . 1 6 3}$ & $\mathbf{. 0 4 3}$ \\
\hline
\end{tabular}

The model parameter statistics are presented in Table 4. Neither of the dummy variables representing the work-life interventions, i.e, the announcement of the rostered day off policy for salaried project-based workers or the work-life balance workshop and subsequent leadership/mentoring session were significant predictors of the work-life 'outcome' variables. Weekly work hours was a significant predictor of overall satisfaction with work-life balance $(\mathrm{t}=-3.473, \mathrm{p}=.003)$, capacity to complete tasks at work $(\mathrm{t}=-2.558$, $\mathrm{p}=.019)$ and capacity to complete tasks at home $(\mathrm{t}=-4.385, \mathrm{p}=.000)$. Routine rostered days off were not a significant predictor of any of the 'outcome' variables. However, the occurrence of long weekends, i.e., a period of three days away from work arising as a result of a public holiday, predicted workers' capacity to complete tasks at home $(\mathrm{t}=2.163, \mathrm{p}=.000)$.

\section{Qualitative analysis of the evaluation workshop data}

Key themes emerging from the analysis of the work-life evaluation workshop are presented in Table 5. Workshop participants were generally positive about the work-life environment within the contracting organization, expressing the view that the organization's efforts support work-life balance. However, several participants expressed the view that more could still be done to improve workers' work-life balance within the contracting organization. Participants perceived that managers were generally supportive of work-life balance. However, a number of participants observed that managers themselves work excessive hours and that this could discourage younger workers from placing limits on their own work hours. The importance of managers acting as role models in the utilization of work-life balance strategies themselves was noted.

Several participants noted that the work-life strategies had not been formally 'packaged' and presented to the workforce. Some participants were new to the organization and unclear about the work-life balance strategies and, in particular, were unclear about expectations about work hours within the organization. Participants suggested a range of methods for raising awareness of the work-life strategies, such as including information about work-life balance in the induction process, reminding staff of strategies, and formalising all strategies into one policy rather than relying on individual managers to communicate information on an ad hoc basis. The issue of industry culture, in particular working hours, was identified as a barrier to utilization of work-life strategies. A number of participants commented upon the need to empower younger workers to utilize work-life balance strategies.

Table 5: Thematic analysis of the qualitative evaluation workshop data

\begin{tabular}{|c|c|}
\hline Theme & Example quotations \\
\hline $\begin{array}{l}\text { 'Realistic' appreciation of } \\
\text { the organization's WLB } \\
\text { initiatives }\end{array}$ & $\begin{array}{l}\text { "At the end of the day if the company doesn't build any buildings well none of us get paid and } \\
\text { that's the fundamental reason why we're at work, but obviously work has progressed beyond } \\
\text { this day and age to pretty advanced down the track where it's actually concerned about your } \\
\text { health, it's actually concerned about your wellbeing, how you're treated at work, the hours } \\
\text { you work and there actually seems to be a far more genuine concern and effort even though } \\
\text { sometimes it, there's room for improvement or things that aren't quite good as they seem." } \\
\text { "I'm not saying it can't improve but really, in my opinion, a lot of substantial initiatives [are] } \\
\text { being made, they've been taken." }\end{array}$ \\
\hline $\begin{array}{l}\text { The importance of } \\
\text { managerial support }\end{array}$ & $\begin{array}{l}\text { "I don't think if you went to a manager in [organization's name] and you explained, 'look I } \\
\text { live a long way away, I'm office based or I'm maybe onsite but in the office. I'm not actually } \\
\text { managing people at seven o'clock in the morning so can I turn up at eight'... I'd be extremely } \\
\text { surprised if someone knocked you back on it". } \\
\text { "I've had certain managers from day one that would help identify that you're doing too much } \\
\text { or take check or whatever. There is a level of genuine sort of concern and empathy towards } \\
\text { balancing [work and life]". }\end{array}$ \\
\hline Managers as role models & $\begin{array}{l}\text { I think some of the senior team probably aren't that good at doing it themselves to be } \\
\text { honest...... so if you're not careful junior people model themselves on people that aren 't good } \\
\text { at it [work-life balance]". }\end{array}$ \\
\hline
\end{tabular}




\begin{tabular}{|c|c|}
\hline & $\begin{array}{l}\text { "It's good to see some of the managers participating in it to make you feel like it is okay to do } \\
\text { it". }\end{array}$ \\
\hline $\begin{array}{l}\text { Communication of WLB } \\
\text { strategies }\end{array}$ & $\begin{array}{l}\text { "I don't think it's been any grand roll out. It's been something that's being tried, we'll give } \\
\text { this a try and I certainly know I live under my little rock and I've got the message, but it } \\
\text { hasn't been a 'come in here sit down' or 'here's a memo that you might like to read' that } \\
\text { explains all the company's initiatives". } \\
\text { "I wouldn't have thought they've been communicated that much. I mean we're aware of them } \\
\text { but there sort of hasn't been a forum where it's been put out to everyone these are the new } \\
\text { initiatives". }\end{array}$ \\
\hline New workers' uncertainty & $\begin{array}{l}\text { We've only been here about two months and I've certainly found it a bit unclear, the working } \\
\text { hours when I started, when to go, when to get here". } \\
\text { "We walked in the middle of all this work life balance and I'm sure that's been the policy for } \\
\text { a while but yes we weren't really told when we started". }\end{array}$ \\
\hline $\begin{array}{l}\text { Need for implementation } \\
\text { consistency }\end{array}$ & $\begin{array}{l}\text { "Different senior staff deal with things differently, so if you're getting the message from your } \\
\text { boss instead of getting the message from the Managing Director you're going to get different } \\
\text { information because they're going to focus on what's important to them. So I mean to get the } \\
\text { policy all in one hit, the details, and it's probably a better approach". }\end{array}$ \\
\hline $\begin{array}{l}\text { Industry culture/structure } \\
\text { as a barrier }\end{array}$ & $\begin{array}{l}\text { There's an old school culture like I used to get when I first worked on site and I did turn up } \\
\text { early but if you were five minutes late you had the old supervisor (say) what's going on here } \\
\text { as you're walking through the door. And until those guys become another generation then } \\
\text { there is a lot of pressure, particularly on young people to conform to that and there's a lot of } \\
\text { old fashioned attitudes to that as well. So any progressive organisations like this that are } \\
\text { more in tune with it, but the construction game is just really difficult I think to get work life } \\
\text { balance in". } \\
\text { "I think it comes back to in that work life balance is a serious discussion about programming } \\
\text { and planning the work. There's a lot of competition on now where companies like ourselves } \\
\text { win or lose the work because they can deliver it three months earlier, and someone says no } \\
\text { that's not going to take us a week we'll get that done in two days and it's really a week's } \\
\text { work, and everybody's got to scramble to condense it because you want, you need to win that } \\
\text { job". }\end{array}$ \\
\hline $\begin{array}{l}\text { Need to actively } \\
\text { encourage younger } \\
\text { workers to use WLB } \\
\text { strategies }\end{array}$ & $\begin{array}{l}\text { "You've got the confidence, or some of us have the confidence to make their own call and } \\
\text { create your own work life balance I think that needs to be encouraged at all levels". } \\
\text { "I think it's actually something that needs actually to be pointed out to some of the young } \\
\text { grads because you will find the grads will sit at a desk for two extra hours doing nothing just } \\
\text { because there's a perception that they should be". }\end{array}$ \\
\hline Enjoyment in work & $\begin{array}{l}\text { "I could be here all night and all day. It sort of becomes like a conscious decision, you have } \\
\text { to say that's enough and I've actually got to do something else outside of work". } \\
\text { "When there's lots happening I have no problem working Saturdays, Sundays, and all hours } \\
\text { during the day, but I do it for self-gratification...I wouldn't necessarily say I'm a workaholic } \\
\text { but there are quite a few passionate people in the building industry that are quite happy to } \\
\text { spend time at work, you're not trying to prove a point you're actually enjoying what you're } \\
\text { doing". }\end{array}$ \\
\hline $\begin{array}{l}\text { Appreciation of a two day } \\
\text { weekend }\end{array}$ & $\begin{array}{l}\text { "I don't mind working a very heavy week if I get that two day break. It just works a lot better } \\
\text { for me". } \\
\text { "I've been site based for a lot of my time over the last year. I suppose here a five day week } \\
\text { has been a lot to me like compared to do doing the six day weeks. That to me is worth more } \\
\text { than salary or money or anything to be honest". }\end{array}$ \\
\hline $\begin{array}{l}\text { Exhaustion following a } \\
\text { six day week }\end{array}$ & $\begin{array}{l}\text { "[The ]problem is you end up doing ten or eleven hour week days, and then the Saturday as } \\
\text { well, so by Sunday you fall in a heap". } \\
\text { "If you've worked a big week you find on a Saturday, or if you work Saturday find on a } \\
\text { Sunday, you're actually mentally exhausted it takes you that day. So if you've got an extra } \\
\text { day like the Sunday you seem to enjoy that more if you're really flat on that Saturday". }\end{array}$ \\
\hline
\end{tabular}




\section{Discussion}

\section{Work hours and work-life balance}

The research reveals a strong inverse relationship between weekly work hours and the quality of work-life balance experiences. Generally, participants indicated working long hours. For example, one participant wrote: "I actually had Friday off even though I worked 51-55 hours this week!' Qualitative comments made by participants indicated that they experience time poverty, resulting in feelings of tiredness and frustration. For example, one participant wrote: "Generally I feel that I cannot get everything done (work and personal) that I want to as there is just not enough time. Subsequently in trying to do so, I find myself to be tired quite regularly." Another commented: "[I am] currently working on a tender, with not enough time, and not enough information."

The fluctuations in work hours and work-life experiences that occurred during the weekly data collection period reveal the dynamic nature of work in the construction industry. In the construction industry context, frequent, repeat measurement-based data collection and the use of longitudinal research designs have considerable advantages in that it can capture the fluctuations in workload that occur naturally in project-based work. Despite periods of high intensity work, the fluctuations in work demands (and hours) can also present an opportunity for respite. As one participant commented: "This is the type of industry where one is either flat out or somewhat quiet, and it can be in the quiet times that we can get some of the home life back." Another (office-based) worker wrote: "Currently tendering has dropped off with regard to intensity, [I am] able to fit-in some other items which would perhaps miss-out, in the normal timeframe of work."

The weekly report data also highlights an asymmetry in the work-life relationship that has been observed by other researchers (see, for example, Geurts et al., 2005). This was also indicated by the stronger negative relationship between work hours and capacity to complete tasks at home than between work hours and capacity to complete tasks at work. One participant expressed this as follows: "There is no way to catch up on lack of sleep or shopping if not up to date on the weekend. So many times the 'work' side disrupts the 'life' side but very rarely is it the other way around."

\section{The impact of the work-life intervention}

Mean scores for all three dimensions of work-family conflict were lower at time two, i.e., after the worklife balance intervention had been implemented in the contracting organization, than at the baseline survey. Similarly, mean scores for work-family enrichment (both work to family and family to work enrichment) were higher following the intervention than they were at the time of the baseline survey. However, with the exception of the decrease in time and strain-based FIW, these differences were not statistically significant.

The time series analysis of weekly report data indicated that neither phase of the work-life balance intervention had a significant impact upon any of the three work-life 'outcome' variables recorded throughout the research period once weekly work hours were controlled for. Notwithstanding these results, the qualitative comments made by participants during the evaluation workshop indicated that workers recognise that substantial efforts are being made to provide an improved work-life balance within the organization and are appreciative of this.

Reasons why an immediate quantitative improvement in the quality of work-life experiences of participants was not evident during the data collection period are not known. However, a number of possible explanations exist. Nielsen et al. (2010) suggest that concurrent context events can hinder or help the implementation of organizational interventions. The intervention period took place in the immediate aftermath of the Global Financial Crisis. Despite the fact that the Commonwealth Government of Australian substantially 'propped' up the economy by investing heavily in the construction industry, private investment in construction projects was dramatically reduced during this period and remains sluggish. In this context, the research took place during a difficult time for the contracting organization 
and many workers were engaged in tendering for work in an economic climate of scarce work and intense competition. It is possible that these context events limited the impact of the work-life strategies.

Blair-Loy and Wharton (2004) also suggest that organizational work-life initiatives can also be of limited effectiveness when implemented in organizational contexts in which there is a culture of long hours or in which job demands are particularly great. The reason for this is that workers who are already putting in very long hours have restricted 'degrees of freedom' to rearrange their work schedules to provide a better 'fit' between work and personal life. Ironically, it is the workers whose work-life balance is most problematic who are least able to make adjustments to their work hours. Future research should seek to investigate the environmental, organizational and job constraints to utilizing work-life strategies in the construction contracting context.

Another plausible explanation for lack of immediate impact of the intervention in the 'weekly report' data is that organizational interventions can take some time to exert a significant effect on working conditions and well-being (Landsbergis and Vivona-Vaughan, 1995). It is quite possible that other changes necessarily precede improvements in work-life balance. For example, enhanced communication about work-life balance, the engagement of workers in participative processes and a growing sense of empowerment among workers may be necessary precursors to more tangible (and quantifiable) improvements in work-life experiences. Nielsen et al. (2010) argue that researchers should evaluate qualitative issues before concluding that an intervention has been ineffective. Indeed, the data collected during the evaluation workshop suggests that positive changes are occurring within the contracting organization. This was reflected in expressions of appreciation that the organization is concerned about work-life balance as workers were being consulted about strategies that would help them. Changes in outcome measures (i.e., the quality of work-life experiences) should be closely monitored and may flow from the positive sentiment created by the participative intervention and continued implementation and refinement of work-life strategies.

\section{Barriers and facilitating factors}

In organizational intervention research, Nielsen et al. (2010) suggest that it is important to evaluate not only the effects of the actual strategies implemented but also the processes which may have facilitated or hindered their implementation. The comments made during the evaluation workshop and also in participants' weekly records, suggest a number of factors that could have improved the effectiveness of the intervention.

First, comments recorded by some participants indicated that a culture of long hours prevailed and some workers did not feel comfortable leaving early. One participant commented: "[I am] a little frustrated with work-life balance this week, as we are in between jobs, there has been a lot of talk about making the most of it being quiet, leave a little earlier if you can, etc. However, even though it is not explicit, the feeling still is that you need to be at work at 7.30 and leave at 5. This is still a 9.5 hour day, which is a long day, even though things are quiet....I don't feel comfortable leaving at say 4pm, which would still be a full 8 hour work day plus $1 / 2$ hour for lunch."

Thus there appears to be a gap between the degree of work hours flexibility available and flexibility actually practiced (Kossek et al., 2006). This may be related to an entrenched 'long hours' culture within the construction industry. The majority of Australian construction industry workers have been socialised into occupational/organizational cultures that equate long hours with commitment and productivity. Changing this mindset is likely to take some time.

The evaluation workshop data suggest that communication about the importance of work-life balance to the organization, the participatory intervention and the work-life strategies themselves could have been stronger. A number of workshop participants commented that the work-life strategies were not formally announced within the organization, resulting in uncertainty about the 'acceptability' of the use of these strategies. It is vitally important that workers are informed about work-life interventions to achieve their participation and 'buy in.' Kirby and Krone (2002) also comment upon the pervasive yet subtle role 
played by communication within organizations in shaping workers' decisions about whether or not to utilize work-life strategies. Managers and coworkers play a key role in communicating the 'acceptability' of strategy use. Some participants identified a degree of 'patchiness' in managers' support for the use of work-life strategies within the organization. It is essential that there is clear communication of the organization's commitment to work-life balance from all managers. To achieve this, it is possible that communication to managers (at all levels) about the work-life intervention and expected organizational benefits associated with the implementation of work-life strategies could help to ensure a consistent managerial approach is taken. In addition, managers may also need to be trained in the skills they will need to implement work-life strategies within their work areas.

A number of workshop participants commented that the contracting organization's newsletter would be an effective medium for providing information about the work-life strategies. Dissemination of success stories throughout the organization, e.g. examples of senior managers who work flexible hours, could also help to frame work-life strategy use more positively and help to overcome negative perceptions about the appropriateness, particularly prevalent among younger workers.

\section{Conclusions}

The research has implications for research and practice. For researchers the results highlight the limitations associated with reliance on cross-sectional surveys for collecting data about work-life balance experiences in the dynamic construction contracting environment. It also shows that an action research methodology provides a useful framework for the implementation and analysis of organization-level work-life interventions. However, the research also highlights the importance of careful evaluation of the effect of work-life interventions as changes in work-life outcomes are unlikely to be immediate. Thus, qualitative indicators of more gradual change processes within organizations should also be used to evaluate the impact of work-life interventions. The research also highlights the need to investigate the cultural context in which work-life interventions are implemented and factors that support and/or impede the utilization of work-life strategies.

For practitioners, the research describes a participatory approach to tackling the work-life balance challenge within construction organizations. Preliminary evidence suggests that this approach can help construction organizations to engage their workforce in a process of devising, implementing and evaluating the impact of strategies designed to support work-life balance. The research provides early evidence that the adoption of a participatory approach to the management of work-life balance creates positive sentiment among workers. However, the research also highlights some important implementation issues, most notably related to communication about the work-life intervention and strategies within the organization. Addressing these implementation issues is likely to contribute to ensuring that potential benefits associated with the implementation of work-life strategies are realised for individual workers, as well as for organizations.

\section{Limitations and future research}

The research was limited in a number of important respects. First, the timing of the weekly report data collection was limited to a period of 25 weeks. Consequently, it is unknown whether improvements in the three 'outcome' variables will be observed in the medium to long term. Second, data were collected in a single contracting organization. Organizations differ in terms of their size, culture and management structure. A large number of intervention studies would be needed before concluding that the participatory work-life intervention described is universally applicable to the construction industry.

\section{Acknowledgement}

This research was funded by the Australian Research Council under Linkage Project Grant LP08820335. 


\section{References}

Aitken, A. and Crawford, L., (2007), Coping with stress: Dispositional coping strategies of project managers, International Journal of Project Management, 25, 666-73.

Allen, T. D., (2001), Family-supportive work environments: The role of organizational perceptions, Journal of Vocational Behavior, 58, 414-435.

Asquin, A., Garel, G. and Picq, T., (2010), When project based management causes distress at work, International Journal of Project Management, 28, 166-72.

Bolger, N., Davis, A. and Rafaeli, E., (2003), Diary methods: capturing life as it is lived. Annual Review of Psychology, 54, 579-616.

Blair-Loy, M. and Wharton, A. S., (2004), Organizational commitment and constraints on work-family policy use: Corporate flexibility policies in a global firm, Sociological Perspectives, 47, 243-266.

Box, G. E. P. and Tiao, G. C., (1975), Intervention analysis with applications to economic and environmental problems, Journal of the American Statistical Association, 70, 70-79.

Breaugh, J.A., and Frye, N.K., (2007), An examination of the antecedents and consequences of the use of family-friendly strategies, Journal of Managerial Issues, 19, 35-52.

Brough, P. and O'Driscoll, M. P., (2010), Organizational interventions for balancing work and home demands: An overview, Work and Stress, 24, 280-297.

Butler, A.B., Grzywacz, J.G., Bass, B.L. and Linney, K.D., (2005), Extending the demands-control model: a daily diary study of job characteristics, work-family conflict and work-family facilitation, Journal of Occupational and Organizational Psychology, 78, 155-69.

Carlson, D. S., Kacmar, K. M. \& Williams, L. J., (2000), Construction and Initial Validation of a Multidimensional Measure of Work-Family Conflict, Journal of Vocational Behavior, 56, 249-276.

Carlson, D. S. , Kacmar, K. M. , Holliday Wayne, J. and Grzywacz, J. G. (2006) Measuring the positive side of the workfamily interface: development and validation of a work-family enrichment scale. Journal of Vocational Behavior $\mathbf{6 8}$, pp. 131-164.

Casper, W. J. and Buffardi, L. C., (2004), Work-life strategies and job pursuit intentions: The role of anticipated organizational support, Journal of Vocational Behavior, 65, 391-410.

Djebarni, R., (1996), The impact of stress in site management effectiveness, Construction Management and Economics, 14, 281-293.

Gottman, J. M. and Glass, G. V., (1978), Analysis of interrupted time series experiments, in Kratochwill, T.R. (ed.) Single Subject Research: Strategies for Evaluating Change, Academic Press, New York, pp. 197-235.

Grover, S. and Crooker, K., (1995), Who appreciates family responsive human resource policies: The impact of familyfriendly policies on the organizational attachment of parents and non-parents, Personnel Psychology, 48, 271-288.

Grzywacz, J. G. and Marks, N. F. (2000) Reconceptualizing the work-family interface: an ecological perspective on the correlates of positive and negative spillover between work and family. Journal of Occupational Health Psychology $\mathbf{5}$, pp. 111-126.

Geurts, S. A. E., Taris, T. W., Kompier, J. S. E., Dikkers, M., Van Hooff, M. and Kinnunen, U., (2005), Work-home interaction from a work psychological perspective: Development and validation of a new questionnaire, the SWING, Work and Stress, 19, 319-339.

Halpern, D. F., (2005), How time-flexible work policies can reduce stress, improve health and save money, Stress and Health, 21, 157-168.

Hanson, G. C. , Hammer, L. B. and Colton, C. L. (2006) Development and validation of a multidimensional scale of perceived work-family positive spillover. Journal of Occupational Health Psychology 11, pp. 249-265.

Hartmann, D. P., Gottman, J. M., Jones, R. R., Gardner, W., Kazdin, A. E. and Vaught, R. S., (1980), Interrupted time-series analysis and its application to behavioural data, Journal of Applied Behavior Analysis, 13, 543-559.

Haynes, N. S. and Love, P. E. D., (2004), Psychological adjustment and coping among construction project managers, Construction Management and Economics, 22, 129-140.

Innstrand, S. T. , Langballe, E. M. , Espnes, G. A. , Falkum, E. and Aasland, O. G. (2008) Positive and negative work-family interaction and burnout: a longitudinal study of reciprocal relations. Work \& Stress 22, pp. 1-15

Kirby, E. L. and Krone, K. J., (2002), “The policy exists but you can't really use it": Communication and the structuration of work-family policies, Journal of Applied Communication Research, 30, 50-77.

Kossek, E. E., Lautsch, B. A. and Eaton, S. C., (2006), Telecommuting, control and boundary management: Correlates of policy use and practice, job control and work-family effectiveness, Journal of Vocational Behavior, 68, 347-367.

Landsbergis, P., and Vivona-Vaughan, E., (1995), Evaluation of an occupational stress intervention in a public agency, Journal of Organizational Behavior, 16, 29-48.

Leung, M-Y., Skitmore, M. and Chan, Y.S., (2007), Subjective and objective stress in construction cost estimation, Construction Management and Economics, 25, 1063-1075

Leung, M-Y., Chan, Y. S. and Olomolaiye, P., (2008), Impact of stress on the performance of construction project managers, ASCE Journal of Construction Engineering and Management, 134, 644-652.

Lindgren, M. and Packendorff, J., (2006), What's new in new of organizing? On the construction of gender in project-based work, Journal of Management Studies, 43, 841-66.

Lingard, H. and Francis, V., (2004), The work-life experiences of office and site-based employees in the Australian construction industry, Construction Management and Economics, 22, 991-1002.

Lingard, H., Francis. V. and Turner, M., (2010a), Work-family conflict in construction: Case for a finer-grained analysis, 
Journal of Construction Engineering and Management, 136, 1196-1206.

Lingard, H., Francis, V. and Turner, M., (2010b), The rhythms of project life: a longitudinal analysis of work hours and worklife experiences in construction, Construction Management and Economics, 28, 1085-1098.

Love, P. E. D., Edwards, D. J. and Irani, Z., (2010), Work stress, support, and mental health in construction, Journal of Construction Engineering and Management, 136, 650-658.

Mohr, G. and Wolfram, H. J., (2010), Stress among managers: The importance of dynamic tasks, predictability, and social support in unpredictable times, Journal of Occupational Health Psychology, 15, 167-179.

Muse, L., Harris, S. G., Giles, W. E. and Field, H. S., (2008), Work-life strategies and positive organizational behaviour: Is there a connection? Journal of Organizational Behavior, 29, 171-192.

Ng, T. S., Skitmore, M. R., and Leung, T. K. C., (2005), Manageability of stress among construction project participants, Engineering, Construction and Architectural Management, 12, 264-282.

Nielsen, K., Randall, R., Holten, A. L. and González, E. R., (2010), Conducting organizational-level occupational health interventions: What works? Work and Stress, 24, 234-259.

Perlow, L.A., (1998), Boundary control: The social ordering of work and family time in a high tech corporation. Administrative Science Quarterly, 43, 328-57.

Randall, R., Cox, T., and Griffiths, A., (2007), Participants' accounts of a stress management intervention, Human Relations, 60, 1181-1209.

Rapoport, R., Bailyn, L., Fletcher, J. K. and Pruitt, B. H., (2002), Beyond work-family balance: Advancing social equity and workplace performance, Jossey-Bass, San Francisco.

Sanz-Vergel, A. I., Demerouti, E., Moreno-Jimenez, B. and Mayo, M., (2009), Work-family balance and energy: A day level study on recovery conditions, Journal of Vocational Behavior, 76, 118-30.

Shockley, K. M. and Allen, T. D., (2010), Investigating the missing link in flexible work arrangement utilization: An individual difference perspective, Journal of Vocational Behavior, 76, 131-142.

Sutherland, V. J. and Davidson, M. J., (1989), Stress among construction site managers: A preliminary study, Stress Medicine, 5, 221-235.

Swody, C. A. and Powell, G. N., (2007), Determinants of employee participation in organizations' family-friendly programs: A multi-level approach, Journal of Business Psychology, 22, 111-122.

Thompson, L. F. and Aspinwall, K. R. A., (2009), The recruitment value of work/life strategies, Personnel Review, 38, 195210.

Thompson, C. A., Beauvais, L. L. and Lyness, K. S., (1999), When work-family benefits are not enough: the influence of work-family culture on benefit utilization, organizational attachment, and work-family conflict, Journal of Vocational Behavior, 54, 392-415.

Van Hooff, M. L. M., Geurts, S. A. E., Kompier, M. A. J. and Taris, T. W., (2006), Work-home interference: How does it manifest itself from day to day? Work and Stress, 20, 145-62.

Wayne, J. H. , Grzywacz, J. G. , Carlson, D. S. and Kacmar, K. M. (2007) Work-family facilitation: a theoretical explanation and model of primary antecedents and consequences. Human Resource Management Review 17, pp. 63-76

Wharton, A. S. and Blair-Loy, M., (2006), Long work hours and family life - A cross-national study of employees' concerns, Journal of Family Issues, 27, 415-436.

Williams, K. J. and Alliger, G. M., (1994), Role stressors, mood spillover and perceptions of work-family conflict in employed parents, Academy of Management Review, 37, 837-58. 